\title{
Els cucs de terra, uns hortolans a l’aula.
}

\author{
Núria Cardet (nuriacardet@gmail.com) Escola Països Catalans (Lleida). \\ Manel Ibáñez (m.ibanez@macs.udl.cat) Universitat de Lleida
}

Els cucs de terra són una de les peces clau de la descomposició de la matèria orgànica de l'hort de l'escola. Les preguntes dels alumnes i la rellevància del tema ens va motivar a treballar els cucs amb els alumnes de cicle mitjà de primària. Fem una breu descripció de com hem treballat amb aquests invertebrats el model ésser viu i la idea de cicle, destacant-ne el cicle de la matèria i el de les plantes.

Paraules clau Hort, cucs de terra, descomposició, cicle de les plantes, cicle de la matèria.

\section{CONTEXTE}

En arribar la tardor i la primavera vivim les transformacions més cridaneres del nostre paisatge urbà i rural. Amb els primers freds $i$ les primeres calors, segons sigui a una o altra estació, les preguntes dels alumnes entren per la porta de la classe i no és qüestió de deixar perdre uns neguits tan interessants. Per això els fruits de la tardor $i$ la caiguda dels fulles són treballs clàssics a l'escola el primer trimestre i l'esclat primaveral amb la sortida de les primeres flors i fulles el segon. La connexió entre uns fenòmens $i$ altres no és evident per a la canalla i involucren dos dels conceptes més estructurants per la nostra comprensió del món: el cicle vital de les plantes (en la relació entre els fruits de la tardor i les flors a la primavera) i el cicle de la matèria en el sistemes naturals (en la relació entre la caiguda de les fulles dels arbres a la tardor $i$ el seu rebrot en acabar l' hivern).

En aquest temps de tardor, en que moltes plantes herbàcies clouen el seu cicle de vida, hem collit noves preguntes al diari de l'hort de 3er de Primària de l'Escola Països Catalans de Lleida: Què li passa a la mongetera en arribar la tardor? Què se'n fa de les restes de l'ésser viu? El cicle vital de les plantes i concretament el camí de les llavors és un tema força aprofundit a primària, ajuda el fet que molts dels processos que determinen el cicle és poden viure dins (germinació de llavors) i fora de l'aula (hort, jardí,...). Però el cicle de la matèria en els sistemes naturals, el procés de les restes de la planta quan sucumbeix, és força menys conegut. Sovint s'accepta que la matèria orgànica és descompon i es dóna per tancat el tema. La descomposició de la matèria orgànica, que retorna el carboni a l'atmosfera i altres elements essencials com el nitrogen i el fòsfor al sòl, és un del processos més transcendents per entendre la vida al nostre planeta. El sòl sosté una xarxa tròfica molt complexa del funcionament de la qual en resulta el reciclatge de la matèria orgànica $\mathrm{i}$ el cicle de nutrients. La descomposició de la matèria orgànica inclou dues fases diferents, (i) una fase activa durant la qual els cucs de terra processen la matèria orgànica, modificant les seves propietats i la seva composició microbiana i (ii) una fase de maduració durant la qual els microbis assumeixen el control de la descomposició del material prèviament processat pels cucs.

Els cucs de terra són un dels descomponedors més accessible i per tant una eina didàctica ben interessant. El context proper (en trobem quotidianament a l'hort), i la rellevància social del tema (el cicle del carboni i les seves implicacions ambientals 
com el canvi climàtic) ens va motivar a presentar els cucs a la canalla de 3 er de Primària provant d'apropar una resposta a les seves preguntes de tardor. Però, com sovint passa, els alumnes van descobrir en la proposta una riquesa que no havíem ni imaginat. Esperonats pel resultat hem decidit fer una breu descripció de com ho hem treballat. Un exemple més de les possibilitats que l'hort, un context ric per aprendre, ens ofereix al llarg de tot l'any.

\section{L'EXPERIÈNCIA PAS A PAS}

\section{a) Descoberta dels cucs de terra}

Entrem a l'aula i allí ens espera un cabàs ple de terra $\mathrm{i}$ algun material vegetal marcit. Seiem al voltant del cabàs i la mestra enceta la conversa sobre què hi pot haver-hi a dins. Surten propostes de materials i ésser vius diversos. Un nen parla dels cucs de terra i la mestra estira del fil. Molts dels alumnes n'han vist al solar al costat de l'escola. La conversa deriva cap a tots els cucs observats algun cop. És una gran família amb més espècies que els populars ocells $i$, per tant, en trobem en hàbitats ben diversos. Reconduïm la conversa cap al cucs de terra, on n'heu vist? $N$ 'hi ha a l'hort? Molts alumnes encara no els han tocat mai.

Decidim abocar el cabàs sobre el terra de la classe i observar si hem encertat les nostres prediccions. Emoció, mirades expectants i... apareixen una munió de cucs colgats entre terra i restes vegetals. Els alumnes més decidits s'abraonen a agafar-ne un, dos,... Però ho fan delicadament, amb cura, gairebé amb tendresa (Figura 1). I un allau de preguntes omplen la classe: On tenen el cap i la cua? Per què s'amaguen sota terra? Viuen molts anys? Què passa si accidentalment se'n talla un? No tenen ulls? Com es poden moure sota terra si no tenen potes? Per on poden passar? D'on han sortit? També un allau de respostes intuïtives els en donen resposta. La conversa és trepidant, plena de contradiccions, prediccions i propostes de treball. La quantitat d'informació bescanviada entre l'alumnat en pocs minuts és impressionant. Una classe ben viscuda.
Passats els primers moments d'emoció observem amb calma com es mouen els cucs per la terra abocada a l'aula i reprenem algunes de les qüestions escampades. Les recollim per escrit i les pengem en el taulell de l'hort: Què mengen els cucs? Com s'ho fan per respirar? Com es fan els seus caus? Hi ha pares i mares? Com són per dins?

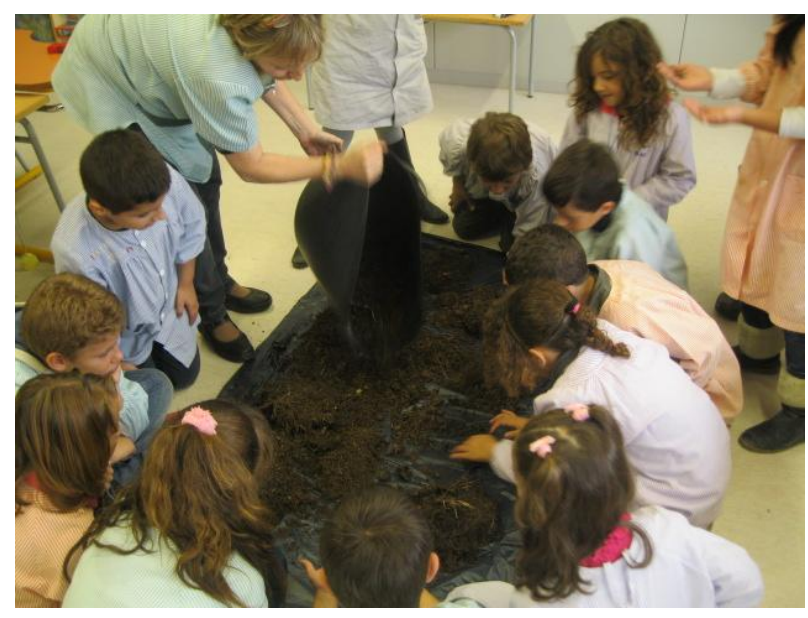

Figura 1: Primer contacte amb els cucs de terra a la classe.

Anirem treballant aquestes interrogants
les properes setmanes i comencem plantejant-nos com donar resposta a algunes qüestions. Podríem investigar què mengen els cucs? Com els afecta la claror? Surt la proposta de fer un terrari i parlem de com construir-lo. Com l'emprarem per investigar l'alimentació dels cucs i la seva percepció de la llum?

Mans a l'obra! Omplim de terra i bona quantitat de cucs una caixa de plàstic transparent. La tapa es forada per permetre la ventilació i tots els laterals els cobrim exteriorment amb plàstic opac. En aquesta petita instal-lació experimental afegirem tot allò que pensem que els cucs poden menjar i no menjar: moltes fulles d'arbres, un melonet collit a l'escola, altres restes de plantes de l'hort, xuxes, taps de plàstic, etc. Remenem el conjunt i compactem amb les mans tot el material i tanquem per dues setmanes. Només obrirem la caixa per regar-la un parell de cops. En una segona caixa construïm un terrari alternatiu, a diferència de la primer 
només cobrim exteriorment dos dels quatre costats laterals. Què passarà en els costats descoberts?

\section{b) El cuc, un ésser viu a l’aula}

Després de les sessions de descoberta dels cucs i veient la riuada de plantejaments abocada pels alumnes tenim una oportunitat per aprofundir en un ésser viu tant proper (viu a l'escola), i tan llunyà a la vegada (el seu hàbitat i la seva morfologia és tan diferent a la nostra, ni tant sols té esquelet). L'observació externa ja és molt interessant. Trobem que el cuc té la boca i l' anus en els extrems oposats, estan dividits en franges o anells molt similars (metàmer), però en destaca un per la seva amplada i gruix, quina funció té? Imaginem com és un cuc per dins i el dibuixem abans de començar a investigar.

És planteja que com a esser viu haurà de realitzar les funcions de relació, nutrició i reproducció adaptat a la vida al sòl. Iniciar la descoberta recollint les qüestions sobre la funció de nutrició sempre és una pauta interessant: Té boca i cul? Per on respira? Té pulmons? Com reparteix els nutrients per tot el cos? Fa pipí? Hem buscat informació sobre els cucs de terra i la sorpresa ha estat important. Els cucs fan tots aquest processos però amb estructures força diferents de les nostres. Aquí rau el potencial didàctic dels cucs de terra, descobrim que es pot fer la mateixa funció però de forma diferent. Tenen òrgans anàlegs als nostres. Per exemple, no tenen pulmons i respiren per la pell. És clar! exclamen els alumnes. Sota terra és més fàcil agafar oxigen per la pell que per la boca! Per això necessiten la pell sempre humida! I s'ofeguen quan s'assequen? En les regions temperades, la majoria dels cucs de terra romanen en diapausa durant l'estiu, i tota l'activitat reapareix quan el sòl adquireix humitat. Aquest comportament és ben familiar per experiència viscuda amb els cargols en anys anteriors. A l' hivern, els cucs redueixen la seva activitat, romanen sempre més o menys passius, però no hibernen. La seva activitat normal i la reproducció s'estableix a la primavera; amb la dessecació del sòl, a l'estiu, comença la seva estivació.
Observant que els cucs tenen la boca i I' anus ens extrems oposats deduïm que el tracte digestiu ocupa tot l'ésser viu. Succionen la terra per empassar-la i, després d'un petit estómac amb pedrer, el llarg intestí prim ha de treballar força per extreure els nutrients d'interès. La collaboració de molt bacteris dins els cuc, tal i com que passa en el tracte digestiu dels humans, és indispensable.
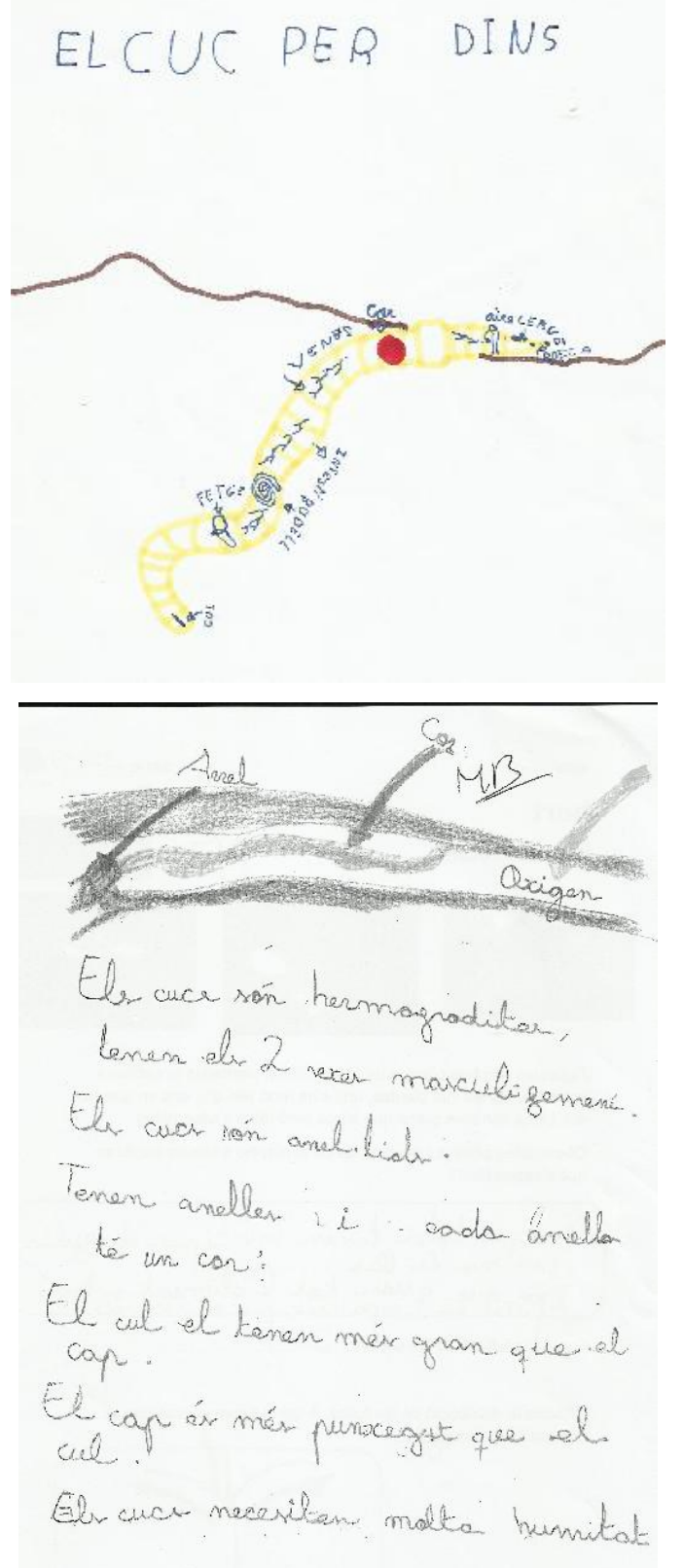

Figures 2a i 2b: Produccions dels nenes i nenes sobre els cucs. 
Però el cuc de terra ens prepara més sorpreses. En partir-ne un accidentalment veiem que la seva 'sang' és força diferent de la nostra. Una altra activitat feta a classe és el dibuix de com s'imaginen un cuc per dins. Després de comentar-los s'ha comparat amb el dibuix de l'anatomia interna proposat per textos experts $i$ han establert relacions vàries ja que com es deia en el paràgraf anterior intuïtivament ho dibuixaven amb les referències i records d'altres animals. També es van escriure textos lliures tal com us mostra el model (Figures $2 \mathrm{a}$ i 2b). La simplicitat del cuc de terra acosta la complexitat del món animal als alumnes.

Parlem de la reproducció, on el clitel juga un paper fonamental ja que segrega les substància que formaran el capoll on es desenvolupa el nou cuc. Però, qui és el mascle i la femella? Els cucs són pares i mares a la vegada. S'aparellen dos individus per transferir els gàmetes masculins a l'altre i cadascun d'ells és fecundat i desenvoluparà el capoll, són hermafrodites. El record i les referències de la canalla a la reproducció d'altres animals treballats com l'estrella de mar ens fan pensar que anem per bon camí. La taxa de reproducció del cuc de terra és la clau del seu èxit en l'evolució: tot i viure més de cinc anys, arriben a la maduresa sexual a les poques setmanes de néixer.

\section{c) El cuc, un descomponedor a P'aula}

Hem deixat treballant als nostres cucs a les seves caixes dues setmanes sense interrupcions $i$ ha arribat el moment d'observar quina feina han fet. Situem la primera caixa en una taula i tots nosaltres al voltant i l'obrim amb un neguit que recorda els dies de Reis a primera hora del matí. Primer fem hipòtesis, recordem les prediccions fetes fa uns dies i n' afegim de noves on incorporem les informacions treballades des de que vam tancar les caixes. Descobrim els quatre costats de la caixa i obrim la tapa superior. Què hi ha? Les fulles, les xuxes $i$ altres elements vegetals han desaparegut! Ni rastre! Algunes arrels han rebrotat i encara hi són. I el meló? Carai de la pell i la polpa no hi ha cap senyal però les llavors continuen tan endreçades com estaven a dins de la fruita. Més encara, amb les bones condicions d'humitat i temperatura ja han germinat i comencen a endevinar-se unes plàntules. I no cal llum? El meló ens dóna bons arguments a una de les qüestions centrals de l'activitat. Què els hi passa a les plantes de l'hort que moren a la tardor? Observem ben bé la diferència entre les llavors i la resta del fruit. Però on està la polpa del fruit, no en queda cap rastre? La descomposició és un canvi químic. Bona part del meló ha estat transformat en gasos: vapor d'aigua i diòxid de carboni, que han abandonat la caixa dia rere dia. Les restes de la digestió dels cucs són impossibles de reconèixer.
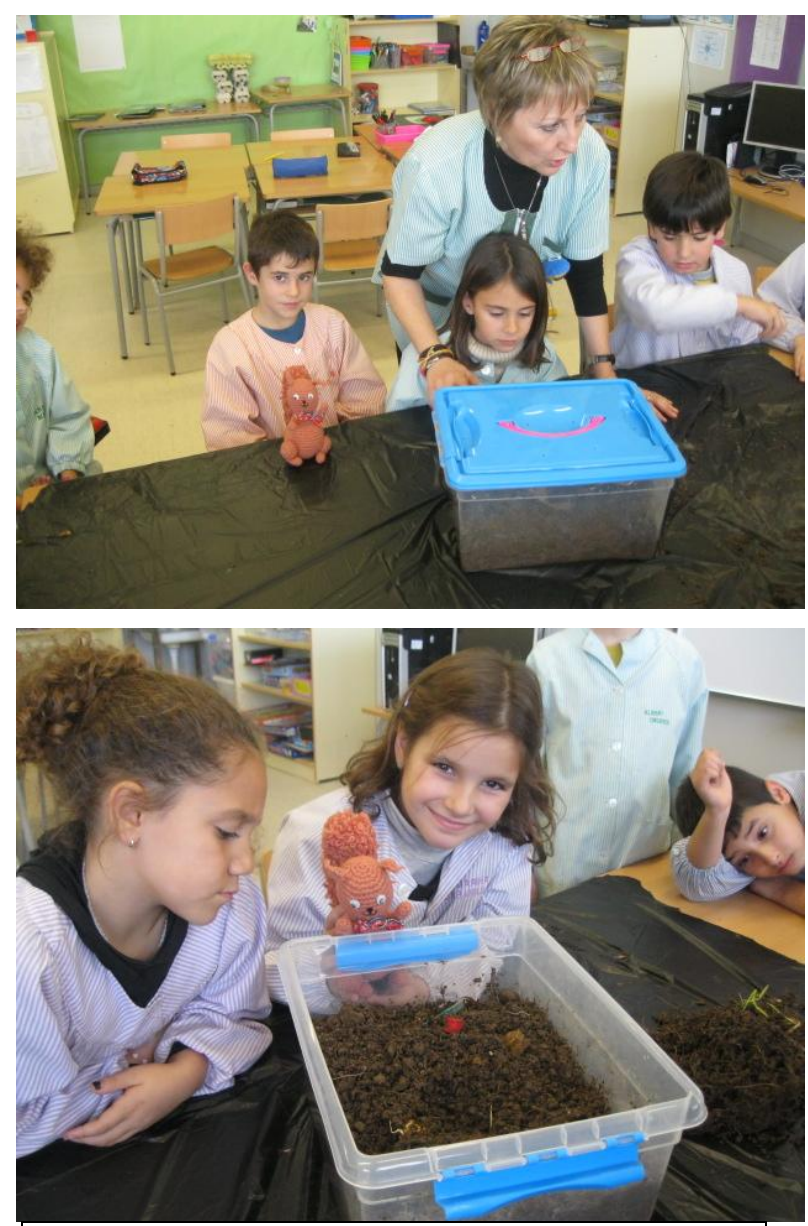

Figures 3a i 3b: Observació del terrari al final de l'experiència.

El alumnes observen la primera caixa per dins i expliquen els canvis físics. Ara la terra està plena de forats, de galeries, en les 
galeries més al fons de la caixa hi ha aigua però en altres no, la terra està molt esponjada, la terra ara sembla feta de boletes, hi ha boletes de totes les mides, grans $i$ petites, són de color ben fosc. Aprofundim en aquest punt plantejant: Qui ha fet aquestes boletes? Per a què les han fet? La canalla contesta decididament que són les caques dels cucs (Figures 3a i 3b). Anant més enllà preguntem: Us sembla que aquestes boletes són el mateix material que la terra que hi havia fa dues setmanes? No, perquè hi ha barrejat les fulles, el meló, les xuxes, etc. També observen altres canvis com l'aparició de floridures. Intuïm que els cucs no treballen sols, tenen ajudants, macroscòpics i microscòpics, amb els que formen l'equip descomponedor. Aquests descomponedors formaran l'humus, terra fèrtil, que podran emprar les futures plantes que conrearem a l'hort. Què passa si no ho fan ells? Recordem que fan els hortolans com el nostre Sr. Paulino, a vegades femen o adoben la terra. El sòl és part del rebost de les plantes, guarda alguns dels ingredients que les plantes necessiten per fabricar-se l'aliment, una part de la matèria orgànica que es cuinen a partir de matèria inorgànica. Però els calen altres substàncies com el diòxid de carboni que obtenen de l'aire i l'aigua. I finalment, l'energia del Sol imprescindible per fer funcionar la cuina. Els cucs i els seus ajudants omplen el rebost però, a vegades, no n'hi prou i el senyor Paulino, quan vol millorar la collita col-labora adobant l'hort.

Fan bona feina els cucs de terra al nostre hort? La resposta és ara unànime i afirmativa. Recollim en un llistat les feines que fan els nostres hortolans del sòl: espongen la superfície del sòl disminuint l'erosió, augmenten la capacitat de retenció d'aigua quan reguem, fan galeries que faciliten l'arribada de l'aire i l'aigua a les arrels i reciclen els nutrients que resten novament a disposició de les plantes en l'humus.

Per observar l'efecte de la claror sobre l'activitat dels cucs acostem a la taula el terrari amb dos laterals descoberts, retirem la protecció dels altres i la tapa superior. Observeu diferències amb la primera experiència? Els nens comenten que en el costat descobert sí hi ha restes de les fulles mentre que en l'altre no. Els cucs defugen la Ilum del Sol!

\section{d) L'humus dels cucs}

La terra en boletes del terrari sembla ben diferent dels materials que varem deixar als cucs els primers dies de l'estada al terrari. El pas dels materials pel tracte digestiu dels cucs ha canviat les substàncies que van engolir i a partir de la matèria orgànica prèvia ens han fabricat l'humus. Podem comprovar a classe que l'humus és un material nou ben diferent les originals? Quina experiència podem plantar-nos? Aviat s'apunten algunes pistes, potser desfent l'humus en aigua, potser barrejant-lo amb vinagre, etc. Enfrontem un segon disseny experimental! Decidim agafar terra de tres espais prou diferents: (1) pati, (2) terra nova preparada per afegir i ampliar l'hort i (3) terrari. Barregem cada mostra de terra amb molta aigua en tres pots diferents. El tres pots queden plens de materials d'aspecte similar a la xocolata desfeta amb tonalitats de marrons diverses. Què passarà? Un cop més parlem i fem hipòtesis. Deixem reposar els pots en un espai de l'aula ben visible. Cada moment disponible, abans i després de les classes, algun observador s'acosta per inspeccionar l'evolució. L'endemà bona part de les terres han precipitat, fins i tot algun nen comenta, qui ha afegit aigua al primer pot? En un parell de dies les diferències entre els pots són meravelloses i dediquem una sessió a comentar-ho. En els tres pots tenim terra precipitada al fons segons la granulometria (sorres, llims i argiles). L'estratificació és ben evident i preguntem, estaven aquests materials en la terra inicial? Com és que no els havíem vist abans? Què els ha passat a dins del pot?

En els tres pots l'aigua queda per sobre d'aquest nivell de sòlids però es presenta amb característiques ben diferents (Figura 4). En el pot del pati (1) l'aigua és transparent i sembla acabada d'afegir de l'aixeta, en el de l'hort (2) és translúcida (ha agafat una mica de color) i en el dels cucs (3) l'aigua és d'un color marró fosc que no deixa passar la llum. El color de l'aigua és molt similar al dels excrements del cucs i la canalla relaciona 
fàcilment les característiques d'aquesta dispersió amb l'humus dels cucs, d'aquest tipus d'humus se'n diu mull. El complex argilo-húmic que es forma de la combinació d'argiles i humus té unes propietats físicoquímiques excepcionals com la capil-laritat que fan possible la vida de les plantes de l'hort. Per això l'aigua queda ben fosca tot i el pas dels dies! Una propietat tan rellevant i difícil és pot observar en un pot a l'aula.

Per sobre de l'aigua només en el pot (2) observem materials surant, és la matèria orgànica sense descompondre expliquen els nens. Novament, ens fa pensar que potser anem per bon camí. Fem anar els sentits i olorem els materials dels tres pots, descobrim una nou misteri! Com tres terres barrejades amb aigua clara poden oferir olors tan diferents? Expliquem i recollim quina olor fa cada pot meravellats amb la seva màgia.

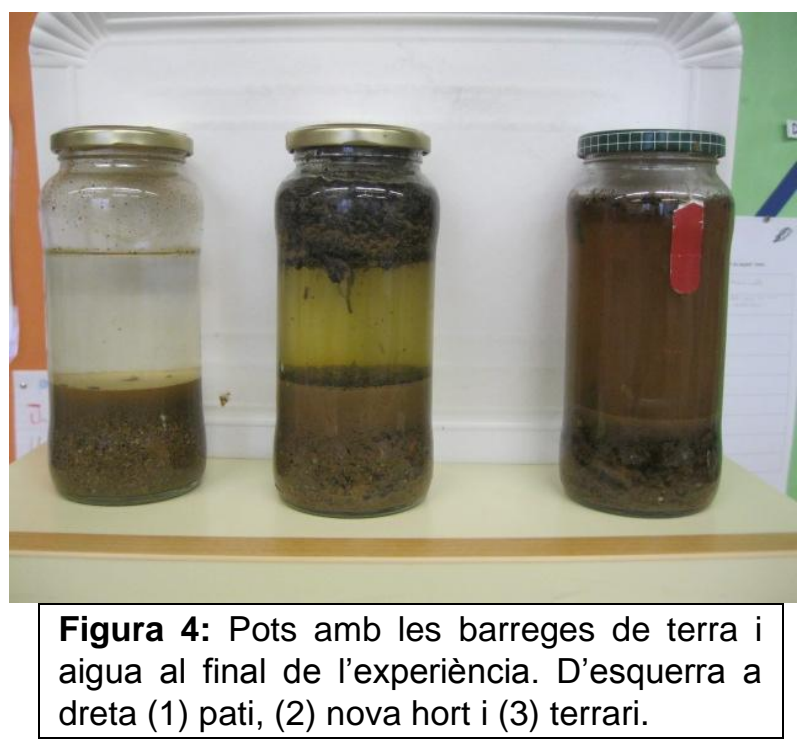

\section{CONCLUSIONS}

Aquest treball es planteja des d'un projecte d'escola on l'hort és un espai educatiu on és possible desenvolupar en l'alumnat competències bàsiques en l'àmbit de les ciències experimentals i d'altres transversals. L'hort ens permet fer un seguiment de fenòmens complexes com el cicle de les plantes $i$ el de la matèria. El reciclatge de la matèria orgànica $i$ el cicle dels nutrients són de difícil comprensió pels alumnes però per la seva proximitat a l'hort $\mathrm{i}$ la importància en els ecosistemes pensem que val la pena abordar el tema a l'escola primària. La introducció dels cucs de terra a l'aula ens ha resultat una eina didàctica interessant per fer-ho. L'aula es ressitua enfront de l'hort i passa a ser un espai on pensem i experimentem sobre fenòmens observats a l'hort. En l'experiència, hem viscut com el alumnes, d'una forma molt senzilla i engrescadora, han intuït com es desenvolupen alguns processos del cicle de les plantes i el cicle de la matèria. Des del punt de vista de les ciències la idea de cicle té una gran importància com a expressió d'una determinada manera d'entendre el funcionament del món. El cicle és una manera potent de mirar, pensar i organitzar molts tipus de canvis.

El treball de descoberta del cuc com a ésser viu no ha estat pas secundari. Idees com adaptació, diversitat i funció han pres força en una aula de tercer de primària. El fet de treballar un animal invertebrat que viu sota terra implica algunes dificultats inicials però amb el temps permet aprofundir el model d'ésser viu aportant diversitat. La seqüència s'ha focalitzat en aquest model d'ésser viu però no hi ha dubte que el medi abiòtic (aigua, aire i sòl) comparteix el protagonisme amb els cucs de terra en aquesta història. Així l'experiència remou i aireja també el model de matèria. Ambdós models continuaran evolucionant conjuntament al llarg de l'educació primària.

El fruit d'una bona experiència sempre és la llavor per la següent. Així l'empenta dels infants i l'entusiasme excavador dels cucs ens han deixat una bona colla de preguntes escrites al taulell: Com van arribar els cucs de terra a l'hort al principi? Si conreem l'hort amb substàncies químiques, els agradarà als cucs? Com es que els cucs no és mengen les llavors $i$ les arrels de les plantes vives?Per què cada pot fa una olor diferent? Obrint nous espais per aprofundir en les interaccions de l'ecosistema hort.

Més enllà dels conceptes de ciències, els alumnes han gaudit molt i han pensat alguns aspectes ambientals de l'hort, han construït textos científics, han compartit preguntes 
noves, s'han ajudat en observar i descobrir, alguns han tocat un cuc per primer cop, tots han intuït que el sòl és un món per descobrir i han imaginat com és la vida sota els seus peus. Finalment, s'han emocionat i han rigut fent ciències a l'escola amb els cinc sentits o millor dit, els mestres junt amb l'alumnat ens hem emocionat $i$ hem rigut fent ciències a l'escola i això no té preu!

\section{REFERÈNCIES}

Domínguez J., AiraM., Gómez-Brandón M. 2009. El papel de las lombrices de tierra en la descomposición de la materia orgánica y el ciclo de nutrientes. Ecosistemas 18 (2): 20-31.

http://www.revistaecosistemas.net/articulo.as $\mathrm{p} ? \mathrm{ld}=601$

Folch, R. (ed.) 1991. Invertebrats no artròpodes. Història natural dels Països catalans. 1991. Ed. Enciclopèdia catalana.

Márquez C. 2006. Pensar i veure el món a través del concepte de cicle. Ciències. Revista del Professorat de Ciències d'Infantil, Primària i Secundària. 4, 32-37. 